\title{
Beaming market simulation to the future by combining agent-based modeling with scenario analysis
}

\section{Christian Stummer $^{1}$ (D) Lars Lüpke ${ }^{1} \cdot$ Markus Günther $^{1}$ (D)}

Accepted: 11 May 2021 / Published online: 12 July 2021

(C) The Author(s) 2021

\begin{abstract}
Agent-based simulation has become an established method for innovation and technology diffusion research. It extends traditional approaches by modeling diffusion processes from a micro-level perspective, which enables the consideration of various heterogeneous stakeholders and their diverse interactions. While such a simulation is well suited to capture the complex behavior of markets, its application is challenging when it comes to modeling future markets. Therefore, we propose a multi-method approach that combines scenario analysis that generates multiple "pictures of the future" with an agent-based market simulation that offers insight into the potential outcomes of today's strategic (technological) decisions in each of these futures. Thus, simulation results can provide valuable decision support for corporate planners and industrial engineers when they are engaged in technology planning. This paper describes the novel approach and illustrates it through a sample application that is based on an industry-related research project on the development and market introduction of smart products.
\end{abstract}

Keywords Agent-based modeling $\cdot$ Scenario analysis $\cdot$ Technology planning $\cdot$ Smart products

JEL Classification $\mathrm{O} 33 \cdot \mathrm{C} 53 \cdot \mathrm{C} 63$

Christian Stummer

christian.stummer@uni-bielefeld.de

Lars Lüpke

lars.luepke@uni-bielefeld.de

Markus Günther

markus.guenther@uni-bielefeld.de

1 Department of Business Administration and Economics, Bielefeld University, Universitätsstraße 25, 33615 Bielefeld, Germany 


\section{Introduction}

In 2019 alone, business enterprises in OECD countries spent more than a trillion USD on research and development (OECD 2021). Accordingly, large amounts of resources are at stake when introducing new products into markets, which challenges corporate technology planners and industrial engineers who have to decide which technologies to pursue and which product features to implement. These decision-makers usually have only a single opportunity to do it right and this sole attempt then drives market success (Golder and Tellis 2004). Moreover, their decision must be made under uncertainty, because adoption and diffusion of innovations in a future market is affected by both macro-economic market development (for an overview of macro-economic forecasts, see Teschner and Weinhardt 2015) and the complex market behavior that emerges as a consequence of the micro-behaviors of diverse market players. Therefore, we propose a multi-method approach that combines macro-economic scenario analysis with micro-economic agent-based market simulation. In this regard, we follow Roper et al. (2011), who suggested that such a fruitful combination can provide robust quantitative projections of the future.

Scenario analysis is prevalent in strategic technology planning (Rigby and Bilodeau 2007), in which such an analysis enables companies to prepare for eventualities and makes them more flexible and innovative (Amer et al. 2013). In our application context, a scenario analysis is used for creating several alternative "pictures of the future." These scenarios are then employed to translate the characteristics of a current market for the parameterization of an agent-based simulation of future markets. Thus, we can analyze the effectiveness or consequences of alternative strategic decisions with respect to possible market developments. In a nutshell, we use the pictures of the future created within the scenario analysis for "beaming" existing data and, thus, the agent-based market simulation into the future.

Agent-based (market) simulation has become an established method for innovation and technology diffusion research (see, e.g., Rand and Stummer 2021; Scheller et al. 2019) and can support decision-makers in this respect. It goes beyond traditional concepts based on analytical approaches, such as the Bass model (1969), by modeling market behavior and innovation diffusion from a micro-level perspective, thereby taking into consideration heterogeneous market players (e.g., producers, intermediaries, or consumers) and their (inter)actions (e.g., word-of-mouth communication). These stakeholders are represented as agents with individual preferences, knowledge (beliefs), and behaviors. Accordingly, innovation diffusion emerges in the course of the simulated period during which agents act and react. For a discussion on the differences between agent-based models and differential equation models (like the Bass model), see Rahmandad and Sterman (2008); the value added of an ABM approach is demonstrated by Banisch and Olbrich (2017).

The proposed multi-method approach constitutes the main research contribution of our paper. In addition, we illustrate its application in a setting that is motivated by a large industry-related research project on developing smart products and production processes (see it's OWL 2020). In this project, we applied our approach for evaluating strategies employed for the market introduction of smart products (for 
intermediate results and the project report, see Günther et al. 2017; Stummer et al. 2018).

The remainder of this paper is organized in the following manner. In Sect. 2, we present our multi-method approach, which consists of two methods, namely, a scenario analysis and an agent-based market simulation. For each method, we suggest one possible approach to proceed when implementing the method. It must be noted that other variants of the method might be selected (e.g., by taking into account additional stakeholders in the agent-based simulation) depending on the specific application case at hand. Thus, the approaches for the scenario analysis and the agent-based simulation, respectively, outlined in Sect. 2 are not fully generic insofar as they would fit any case, but their application spectrum goes beyond a single specific application. Then, in Sect. 3, we describe the sample application and its parameterization and discuss computational results and corresponding managerial insights. In Sect. 4, we conclude the paper with a summary, a discussion of remaining limitations, and an outlook of promising avenues for further research.

\section{The multi-method approach}

The main idea behind the multi-method approach proposed in this paper is to study market behavior for several strategic alternatives (e.g., with respect to the level of smartness functionality with which forthcoming new products should be equipped) in several possible futures (e.g., with respect to consumer preferences in these markets). To this end, parameters for the market simulation are adapted according to the pictures of the future from the scenario analysis. Then, the agent-based market simulation is run for each combination of a future market and each of the strategic alternatives. Thus, decision-makers are provided with insight into the effectiveness of implementing a particular strategy in each of the alternative futures. Figure 1 provides an overview of this multi-method approach.

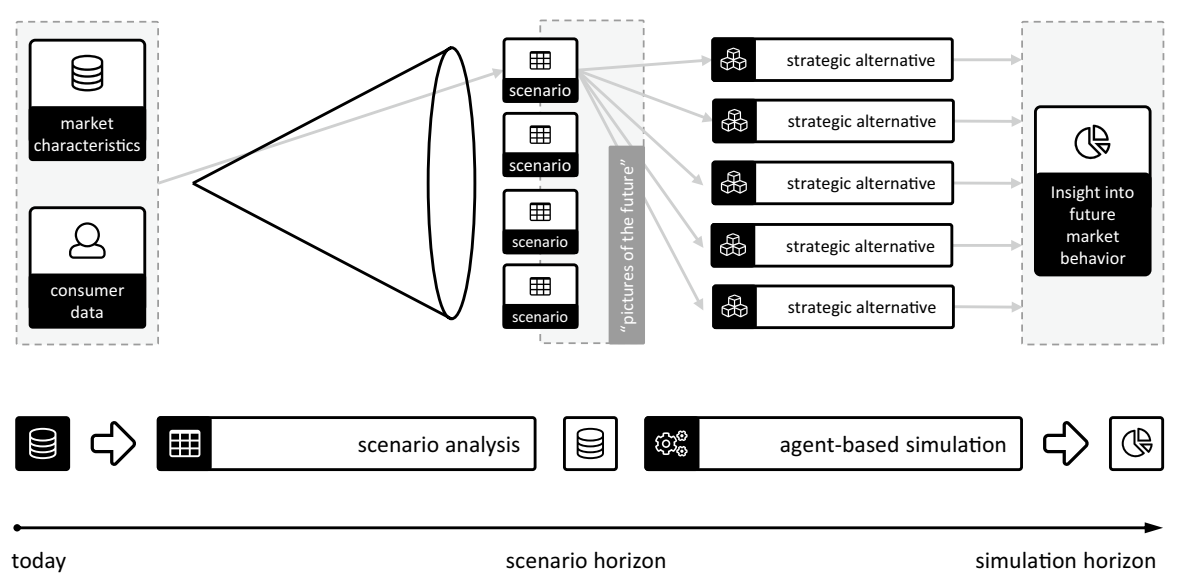

Fig. 1 Framework of the multi-method approach 


\subsection{Scenario analysis}

Scenario analysis as a management tool for strategic planning dates back to "scenario writing" developed by Kahn and Wiener (1967). In the decades ever since, various approaches have been proposed that can be classified into three groups: (i) intuitive logics, (ii) the probabilistic modified trends methodology, and (iii) the French approach of "la prospective". An in-depth overview of diverse concepts of scenario analysis is provided by Amer et al. (2013), Bishop et al. (2007), and Bradfield et al. (2005).

The intuitive logics approach, which is also referred to as the "Shell approach" because of its origin at Royal Dutch Shell (Wack 1985), is considered the de facto "gold standard of corporate scenario generation" (Millett 2003) and the one approach to scenario planning applied by far the most commonly (Derbyshire and Wright 2017). It describes several futures each of which result from a logical combination of assumptions regarding the development of a set of influencing factors. The scenarios are internally consistent but they are limited by the knowledge, commitment, and communication skills of the involved persons (Huss and Honton 1987). In our work, we follow the intuitive logics approach.

To this end, we adopted the process of scenario development by Fink and Siebe (2011), which is based on earlier works by Gausemeier et al. (1998) and Fink and Schlake (2000). This process is illustrated in Fig. 2.

In the first step, creativity techniques (e.g., brainstorming or mind-mapping) are applied for identifying internal as well as external influence factors (the latter referring to, for example, the industry or global environment). An influence analysis (see, e.g., Godet 1987; Schlange 1995) can then be used to retrieve 16-20 of the most relevant key factors.

In the second step, possible developments of these key factors-so-called "projections"- are systematically identified by using various sources and types of information. Two to four (extreme) projections per factor are derived.

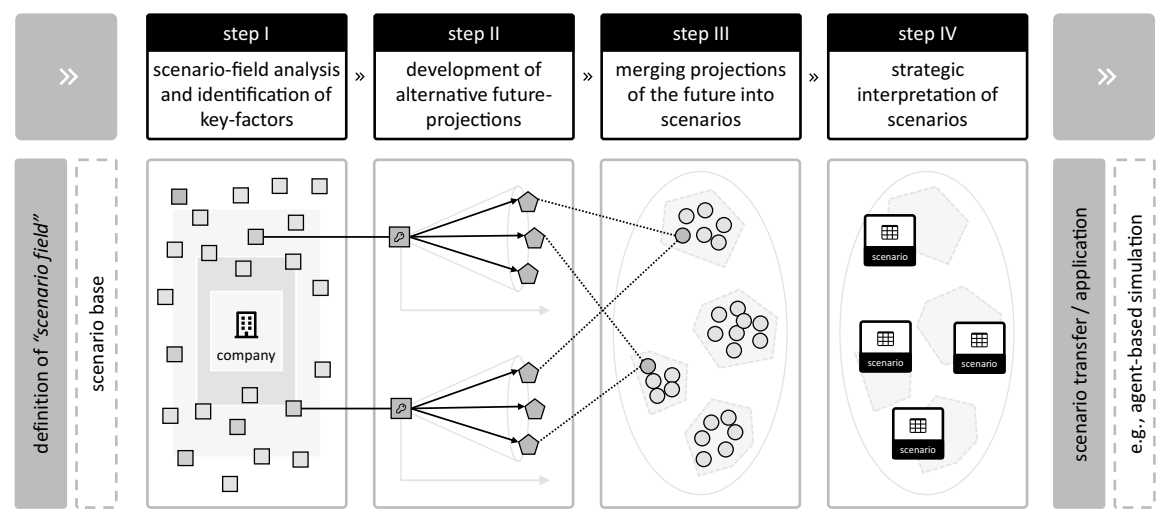

Fig. 2 Scenario development (following Fink and Siebe 2011) 
In the third step, these projections are bundled and evaluated through a consistency analysis. Reasonable bundles are clustered, and scenarios are created from these clusters.

In the fourth step, scenarios are interpreted and summarized either as a written description of the respective future or transformed to a literal picture of the future in form of a visual presentation or a brief video.

\subsection{Agent-based model}

In an agent-based model, agents represent stakeholders such as natural persons (e.g., consumers or opinion leaders), more abstract entities such as companies (e.g., producers, intermediaries, points of sale), or policymakers, who may promote certain behavior through incentives (e.g., subsidies). These agents act according to their aims and needs (e.g., they purchase a product) and they interact with others (e.g., consumers among themselves when engaging in word-of-mouth communication). An introduction to agent-based modeling and simulation can be found in Macal (2016). Applications of agent-based models are particularly popular in research on innovation diffusion (a frequently cited review is provided by Kiesling et al. 2012; an illustrative application case is described by Stummer et al. 2015) and other fields from the social sciences (for an overview, see Klein et al. 2018; for marketing, in particular, see, e.g., Rand et al. 2018).

The entities taken into account in the agent-based model used for our multimethod approach (see Sect. 2.2.1) as well as their dynamics (see Sect. 2.2.2) are depicted in Fig. 3. An in-depth description of algorithms as well as a full list of parameters, variables, functions, and indices is provided in the online appendix.

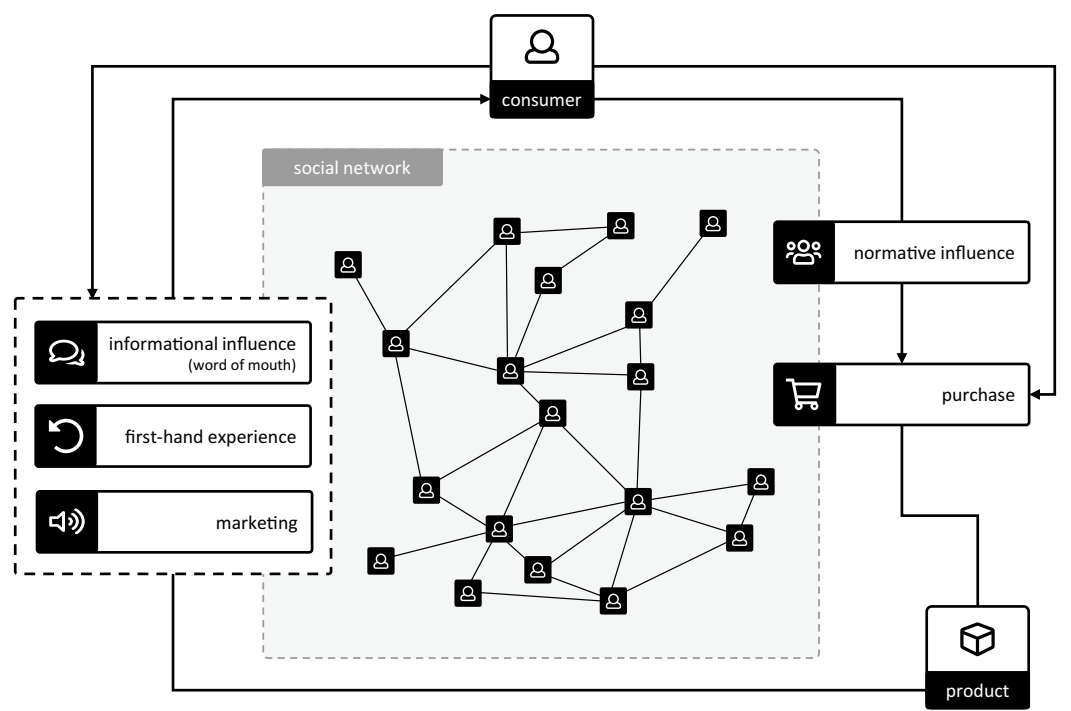

Fig. 3 Entities and dynamics in the agent-based model 


\subsubsection{Model entities}

Products $P$ indexed by $p$ are defined in the model by a global set of attributes $A$ indexed by $k$. The composition of attributes (e.g., the capability to use the smart grid) and their individual levels (e.g., "level of smartness" with respect to autonomy, adaptability, reactivity, multi-functionality, human-like interaction, and ability to cooperate; see Rijsdijk and Hultink 2009) can differ between products. Products can be introduced to the market at different times.

In accordance with the "bounded rationality" in agent-based simulations (Epstein 1999), the availability of products, their attributes, and capabilities are not necessarily known by the consumers because the true performance of product attributes may not be instantly observable. Accordingly, this information must be communicated, for example, through word of mouth between peers or through second-hand experience (e.g., by reading online reviews). It is only once consumers adopt a product that they learn about its attribute levels through first-hand experience.

Consumers $C$ indexed by $i$ communicate with their peers, thereby exchanging information on their beliefs regarding products or attributes, and consumers purchase products. Their behavior in our agent-based simulation relies on the "beliefs, desires, and intentions (BDI)" architecture by Bratman (1987), which is presumably among the best known and most studied models of practical reasoning agents (Baptista et al. 2014).

Consumers form beliefs regarding product attributes belief $_{i, p, k}$, which ultimately determine their utility values $u_{i, k}^{\text {attr }}(\cdot)$. As a prerequisite to let product $p$ or attributes $k$ play a role in the utility calculation, a consumer must be aware of the existence of the product (i.e., awareness ${ }_{i, p}^{\text {prod }}=1$ ) and the respective attributes (i.e., awareness $_{i, p, k}^{\mathrm{attr}}=1$ ). It is noteworthy that when a new product is introduced to the market, consumers have no awareness of the product and the new attributes it may have. The awareness as well as their beliefs for a product and its corresponding attributes must still be created through (i) marketing activities, (ii) individual communication with their peers, or, after the purchase, (iii) their own first-hand experience.

Once a need to purchase a product arises, consumer agents calculate utility values for all products that they are aware of and that are available, and then the consumer agents (re)purchase the product that provides the highest utility value. The purchase decision is made in accordance with the five stages of adoption described by Rogers (2003): (i) learning about the existence of a product and its basic functions ("knowledge phase") by word of mouth or marketing activities; (ii) forming an opinion based on given information ("persuasion phase"); (iii) deciding whether to adopt the product ("decision phase"); (iv) using the product ("implementation phase"); and (v) collection of information to reaffirm the decision ("confirmation phase") by firsthand experience.

The social network describes which agents are acquainted and, thus, interconnected with which other agents. Connections between agents represent bi-directional communication channels through which information is exchanged by word of mouth. 
Moreover, normative social influence might be exerted between agents who are directly connected. A social network can be generated, for example, by the algorithm developed by Watts and Strogatz (1998) to create a small-world network or by the algorithm developed by Barabási and Albert (1999) to create a scale-free network. Both algorithms create networks that match typical characteristics of social networks (i.e., small diameter, highly clustered, numerous hubs), albeit to different extents. The decision for one or the other depends on the specific application, as different markets imply different network structures of consumers (Bearden and Rose 1990); for an overview, see Negahban and Yilmaz (2014). These generic network generation algorithms can also be extended if necessary. For example, a BarabásiAlbert type network can be adapted in a manner in which the possibility of a connection between consumers (and thus their relationship) increases with their spatial proximity (e.g., Stummer et al. 2015) or takes into account a "homophily bias" which creates a tendency that agents mostly interact with like-minded others (e.g., Backs et al. 2019; Mäs and Flache 2013; for a review on the related field of opinion dynamics, see Banisch and Olbrich 2019; Hegselmann and Krause 2002).

\subsubsection{Model dynamics}

The most prominent dynamics in our model stem from the social influence among consumers within their social network and from the purchasing process. First-hand experience and marketing also play a role.

Social influence through peers in the social network (also known as "social conformity") can have a substantial effect on consumers (Butcher et al. 2002; Cialdini and Goldstein 2004; Delre et al. 2010; Schwering 2017). In the recent past, the impact of social influence has increased, not least because of social media and other new communication opportunities (Aral and Walker 2014; Risselada et al. 2014). Social influence can roughly be divided into two dimensions: (i) informational influence, which refers to accepting information obtained from others as evidence of reality; and (ii) normative influence, which occurs out of the desire to conform with others' expectations (Deutsch and Gerard 1955).

Informational influence in our model mainly refers to the information exchange among consumer agents (word-of-mouth communication) and may influence them in two ways. First, consumers take notice and become aware of products or product attributes that they have not known before. Second, the consumer agents' valuation of a product or product attribute is updated with additional information. Possible interlocutors are determined by the social network in which consumers are embedded.

Procedurally, communication events are randomly triggered between two consumers $i$ (receiving agent) and $j$ (sending agent), who are connected directly within the social network. Our model encompasses three kinds of communication: (i) information exchange regarding one product and all its attributes; (ii) information exchange regarding one attribute encompassing all corresponding products; and (iii) information 
exchange regarding one explicit product-attribute pair. After consumer $j$ has randomly selected a product or product attribute as the communication topic, communication takes place and the belief of consumer $i$ is updated with the received information from consumer $j$ based on an update rule of weighted average. To this end, the information is individually weighted, according to the credibility of the consumers with each other $\left(w_{i, j}^{\text {wom }}\right)$. The aggregated (weighted) information on each product-attribute pair $(p, k)$ obtained by consumer $i$ thus far (i.e., before the current communication event takes place) is represented in belief $f_{i, p, k}^{\text {attr }}$. In addition, the sum of weights of prior pieces of information is stored in weight $t_{i, k, k}$. The updated belief of consumer $i$ can then be calculated as

$$
\text { belief }_{i, p, k}^{\mathrm{attr}}:=\frac{\text { belief }_{i, p, k}^{\mathrm{attr}} \cdot \text { weight }_{i, p, k}+\text { belief }_{j, p, k}^{\mathrm{attr}} \cdot w_{i, j}^{\mathrm{wom}}}{\text { weight }_{i, p, k}+w_{i, j}^{\mathrm{wom}}}
$$

and weight $_{i, p, k}:=$ weight $_{i, p, k}+w_{i, j}^{\text {wom }}$. Accordingly, it is relatively easy to affect the opinion of a consumer agent that has not received much information regarding attribute $k$ of product $p$ yet (i.e., a consumer agent $i$ with a low value for weight $t_{i, p, k}$ ), while it requires plenty of diverging information from trustworthy sources to achieve the same for an agent that feels very confident in its belief due to the fact that this belief is based on substantial information obtained in the past.

Obviously, consumer $j$ must be aware of the selected product and product attribute in order to provide information about it. After the communication, both agents are aware of the corresponding product or attribute.

Normative social influence occurs out of the desire to be liked and accepted and, thus, people strive to conform with the expectations of others (Deutsch and Gerard 1955). According to the social impact theory by Latané (1981), the impact of social influence is based on group size, importance of group affiliation, and spatial as well as temporal proximity of other group members. Therefore, we focus on the innermost circle of acquaintances and use the share of direct peers who own a particular product as a proxy for social influence norm $_{i, p}$ (which is similar to the approach by van Eck et al. 2011) with

$$
\text { norm }_{i, p}=\frac{\sum_{j=1}^{N}\left(\text { connected }_{i, j} \cdot \text { own }_{j, p}^{\text {prod }}\right)}{\sum_{j=1}^{N} \text { connected }_{i, j}}
$$

and binary parameter connected $d_{i, j}$ indicating whether or not consumers $i$ and $j$ are directly connected in the social network (note that connected $_{i, j}=0$ if $i=j$ ), and binary variable $o w n_{i, p}^{\text {prod }}$ indicating whether a consumer $i$ possesses the product $p$.

Product purchase is initiated when an existing product reaches the end of its life or as a result of other triggers such as the desire to own a "better" product. Once a consumer agent has decided to purchase a product, the agent considers all available products that the agent is aware of. The decision for a particular product is driven 
by (i) the agent's beliefs regarding the performance of a product under consideration with respect to all the (known) product attributes and by (ii) the normative social influence. Both aspects are taken into account in the consumer agent's utility function

$$
\begin{aligned}
\text { utility }_{i, p}^{\mathrm{prod}}=\operatorname{awareness}_{i, p}^{\mathrm{prod}} & \left(\text { norm }_{i, p, t} \cdot w_{i}^{\mathrm{norm}}\right. \\
& \left.+\sum_{k}^{K}\left(u_{i, k}^{\mathrm{attr}}\left(\text { belief }_{i, p, k}^{\mathrm{attr}}\right) \cdot \text { awareness }_{i, p, k}^{\mathrm{attr}}\right)+\epsilon\right) .
\end{aligned}
$$

The consumer agent's individual part-worth utilities for a product's attributes are represented by function $u_{i, k}^{\text {attr }}(\cdot)$. This function may assume various forms. In our sample application described in Sect. 3, we use a piecewise linear utility function with agent-specific part-worth utility values as the bending points. The strength of impact through normative influence is provided through the (individual) parameter $w_{i}^{\text {norm }}$. Binary variables awareness $s_{i, p}^{\text {prod }}$ and awareness $_{i, p, k}^{\text {attr }}$ indicate whether or not the consumer agent is aware of the existence of a product $p$ and its attributes $k$, respectively. Finally, the (small) stochastic error term $\epsilon$ stands for the possible existence of additional influence factors that have not been explicitly considered.

First-hand experience is formed after purchasing a product. Technically, this is modeled as another belief update, as described in Equation 1 but with belief $f_{j, p, k}^{\text {attr }}$ being set to the "true" performance values and weighting factor $w_{i}^{\text {fhx }}$ being rather high.

Marketing activities can differ in terms of the addressed product attributes, their geographical availability, and their credibility (for examples, see Wakolbinger et al. 2013). When applied, they function in a similar manner as word-of-mouth communication. The information injected in a consumer agent's information base belief $f_{i, p, k}^{\text {attr }}$ can be set to any value by a respective marketing agent. However, more often than not, the credibility of such information - that is, the value set for $w_{i}^{\text {mark }}$-is rather low. Correspondingly, the effectiveness of marketing in shaping the beliefs of consumers is typically small, particularly so in cases in which consumers have already received information from more trustworthy sources. Nevertheless, marketing activities can be valuable in raising awareness for new products or new product attributes (e.g., novel smartness functionality).

As our application is concerned with strategic technology decisions that lead to novel products being introduced into one of the markets described in the scenarios, marketing activities (including price strategies) do not play a major role therein. Moreover, planning marketing activities has a considerably shorter time horizon than that of technology planning decisions. Therefore, only basic marketing activities are considered in the market simulation (e.g., for making some consumers aware of the new product and the novel product attributes). 


\section{Sample application case}

\subsection{Setting the scene}

Our exemplary application is based on an actual case on which we worked together with three other organizations - that is, two consulting agencies and one academic institution other than ours, all of which with strong competencies in scenario analysis, while we contributed expertise in agent-based modeling-for a well-known and long-established incumbent firm. This firm is active in a consumer goods market (i.e., domestic appliances), in which it generates annual sales of several billion Euros. The case we were working on, concerned a particular market segment in which the company holds a dominant position. There, this company is not threatened by competitors, but it is also practically impossible for the company to substantially increase its already extraordinarily high market share. For our sample application (and in accordance with the cooperation partners in this company), it is therefore reasonable to assume a market that-at least for the time covered by the market simulation-is stable insofar as consumers will only choose among the products offered by this company. It must be noted that this favorable setting does not hold true in the same manner for all other market segments in which the company is active. Consequently, in different settings, the agent-based model would need to take into account alternative product offerings (for an example on how this can be implemented, see Stummer et al. 2015).

The company is currently in the process of proactively tackling challenges that arise in the course of its digital transformation. Among other decisions, management needs to decide upon the level of smartness functionality with which the forthcoming family of products shall be equipped. This decision determines corresponding development projects that, after four to five years, result in new products, which then can be introduced into market. Of course, managers take into account cost (e.g., for product development or advertising during market introduction) and respective product profitability when making this decision. However, we did not get such internal data because prospective company earnings did not make a difference for the results of our market simulation. Accordingly, in our project, we were not asked to recommend a particular strategy alternative (and we were not aware about which one was ultimately selected) but to "just" provide decision-makers with simulation results regarding market behavior for each combination of strategy and scenario; afterwards, internal staff calculated cost as well as overall profit and both (and probably additional factors) certainly played a role in selecting the strategy to be pursued.

This particular market is also special in that the number of units sold is more or less constant since each household needs exactly one unit and only replaces it once their existing unit fails. A washing machine may serve as an illustrative example for such a product, as it is very unlikely that someone would discard a fully operational washing machine just because a new model is available that provides some smartness functionality. However, once the old machine is broken, smartness functionality might influence the purchasing decision for a replacement model (and by then such a decision is made pretty swiftly). The price of each type of product is 
determined by the company. This target price is based on market research and decades of experience with the market segment; thus, the price is not driven by the product's lower or higher level of smartness functionality. Note that target prices still can differ between product types (e.g., a premium version is more expensive than a standard version). As this is a company policy, price strategies were excluded from considerations. However, consumers might opt for a different type of product (e.g., a smart variant instead of the non-smart traditional one or a premium variant instead of a standard version) if they perceive a value added in some of its features (e.g., a high level of smartness functionality) and are willing to pay the higher price. Nevertheless, consumers are likely to stick with the brand: there is an internal firm saying that a customer who previously purchased a product from this company is likely to (almost) always also purchase the replacement product from this particular company; in other words, customer loyalty is extraordinarily high.

To sum up, the benefit for the company of employing the multi-method approach introduced in this paper lies in receiving information regarding market behavior for each combination of possible strategy alternative and future scenario. This information is then (internally) used for further calculations (e.g., with respect to expected overall profit) and, ultimately, supports the decision for a strategy, which entails corresponding activities (e.g., projects to develop the necessary functionalities). In this sample application case, we closely followed the company's lead with respect to what to model (e.g., consideration of population distribution since they know that word of mouth most often occurs between consumers within the same geographical region) and what not to model (e.g., competition or pricing strategies, for the reasons outlined above); in other application cases, different market characteristics or choices of action might play a role and, thus, would require corresponding adaptions of the agent-based market model. Further, it was evident that-in accordance with the company's ambition of furthering its digital transformation, which includes offerings of smart products and services - the next product line must be equipped with smartness functionality.

Such smart products can be understood as cyber-physical devices, which have both tangible (i.e., hardware) and intangible (i.e., software) elements. Raff et al. (2020) provide a discussion of different conceptualizations of smart products that can be found in existing literature. They distinguish between four product archetypes - that is, (i) digital, (ii) connected, (iii) responsive, and (iv) intelligent products. The smart products considered in this sample application case are obviously all at least on the level of digital products. They might also be connected to the smart grid, which upgrades them to the level of connected products. When being equipped with both a high level of smartness functionality and smart grid capability, they can be classified as responsive products. None of them fall in the most-sophisticated category of intelligent products.

In the case at hand, the company currently offers two product lines-namely, a standard product line and a premium product line, each comprising several closely related product variants. For the purpose of this market simulation (and in accordance with our partners from the company), it was sufficient to merely distinguish between a standard product and a premium product. The main difference between these two products lies in a few features (e.g., noise emission, material, 
service availability) that in our sample application case will be subsumed as "quality". Further, the two products differ in price set by the company. Thus far, none of these two products is capable of utilizing information regarding energy prices provided through the smart grid, which is not available as of today but is assumed to be in place by the time a new generation of products is introduced into the market. The products from this new generation might have the capability to take advantage of the smart grid. Products from the new generation will also be equipped with a few smart functions. The company has already decided to stick with its traditional strategy of offering both a standard product and a premium product and, thus, to develop two types of such smart products, which are hereafter referred to as the smart-standard product and the smart-premium product; it was not an option to develop only the smart-standard product or only the smart-premium product (or none of them).

Therefore, the open decisions are (i) whether any of the new products (or even both) must be equipped with the capability to be connected to the smart grid and (ii) whether they must provide the smartness functionality at a low or high level (the two levels are used in this application example for the sake of simplicity, while additional variants of smartness levels are possible). As already mentioned, these decisions also affect the required level of expenditures for research and development, which has an effect on the overall profit when implementing a particular strategy. However, this does not play a role for the application case as, in the course of technology planning, the company "only" wishes to learn about prospective market diffusion for each of the possible pairs of a smart-standard and a smart-premium product (see Sect. 3.4 for a description of the strategy alternatives) in possible futures being described through scenarios (see Sect. 3.2). The agent-based market simulation (including validation and parameterization) is described in Sect. 3.3, computational results are presented in Sect. 3.5, and managerial insights are discussed in Sect. 3.6.

\subsection{Scenario analysis}

Since the forecasting horizon of five years-when the new generation of smart consumer products are supposed to be introduced into market - can be considered rather long, given that consumer behavior and technology change may evolve in different directions during this time, we account for the variety of possible futures through four scenarios. While it cannot be expected that any of these four scenarios will perfectly mirror the "true" future, the scenarios nevertheless encompass the major future trajectories and can, thus, serve as a means for providing support for the strategic decisions under discussion.

The scenarios used in this sample application are based on sectoral scenarios for the energy market that have been developed as part of the leading-edge cluster project itsowl-VorZug (it's OWL 2020) by the consultant agencies ScMI and UNITY as well as by the HNI at Paderborn University (a detailed description of these scenarios is provided by Frank and Echterhoff 2018). Scenarios 3 and 4 are-in varying degrees-rather optimistic with respect to market opportunities for smart products: 
In Scenario 3, technological change is accepted by consumers and smart products are on the verge of a breakthrough. Regional expansion of smart grids and high innovative strength have a positive effect on the introduction of smart products. Scenario 4 describes a future in which smart products are already the "success story" and smart grids are available nationwide. Consumers and companies both show a high interest in smart products, which are present throughout. In contrast, Scenarios 1 and 2 are more pessimistic: In Scenario 2, companies react very inertly, although consumers show interest in technological change and smart products. Consequently, consumers lose interest in smart products and a lack of implementation strength leads to stagnation of smart grids. Scenario 1 is characterized by a lack of innovation dynamics and missing awareness for technological change; consumers have lost confidence in smart products.

\subsection{Market simulation}

The agent-based market model described in Sect. 2.2 formed the core of an agentbased simulation tool, which was implemented in AnyLogic (2020). Figure 4 depicts entities and dynamics used in our application case.

First, we tested the simulation tool with data we received about market introduction and market diffusion for a different product from the same company. This product has been introduced into market a few years before. Our approach with respect to verification and validation of the simulation is described in Sect. 3.3.1.

Then, the parameterization for the sample application was done for both consumers and products as described in Sects. 3.3.2 and 3.3.3, respectively. For this purpose, from each of the developed scenarios, a parameter set for the agent-based

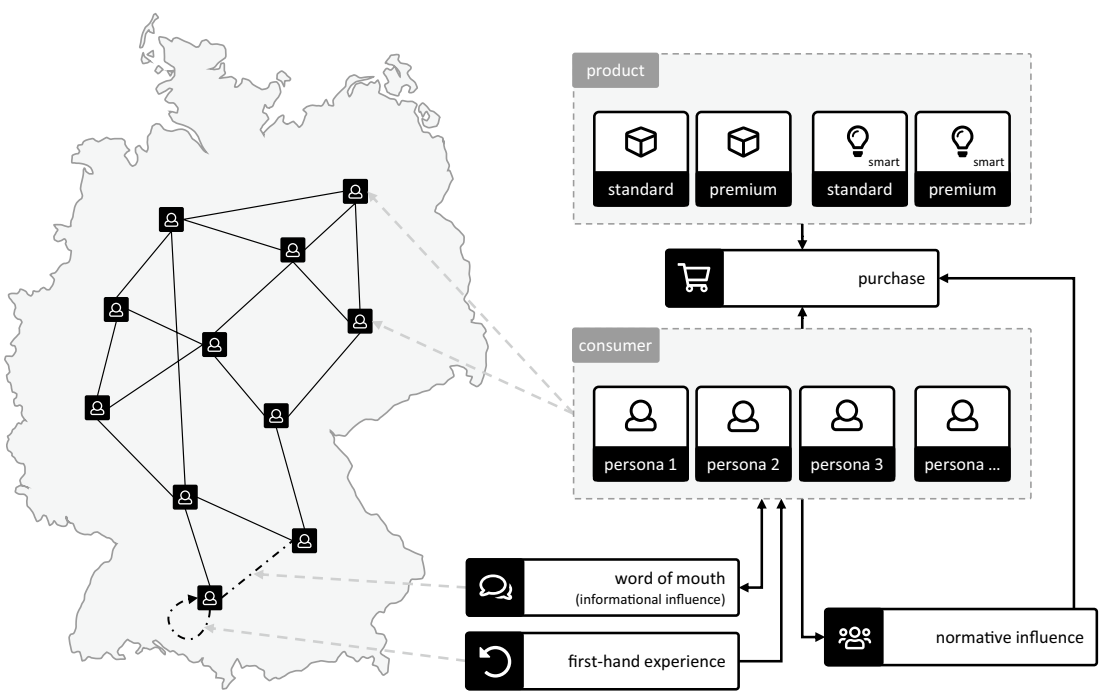

Fig. 4 Entities and dynamics in our sample application 
market simulation is derived and, thus, the market simulation is "beamed" into the respective picture of the future.

\subsubsection{Verification and validation}

Verification and validation of an agent-based simulation model is vital for creating trust in its results. Although it is impossible to completely verify or validate a model (Grimm and Railsback 2005), it is still necessary to make an effort to achieve the best results possible in this respect (for an in-depth discussion see, e.g., Fagiolo et al. 2007; Knepell and Arangno 1992; North and Macal 2007; Ormerod and Rosewell 2006).

In our approach, we followed the guidelines for rigor in agent-based modeling described by Rand and Rust (2011). For verification purposes, we extensively documented what has been modeled and why we have decided to do so; we performed programmatic tests; and we ran several test cases. For validation purposes, we began with a micro-face validation process during which the individual behavior of agents, as captured in the simulation logs, is analyzed; and we checked whether individual decisions are plausible and correspond to general assumptions. The same holds true for the social network that has been generated. With respect to a macro-face validation, we found that the aggregate pattern generated by the simulation runs corresponds to stylized facts for the innovation diffusion pattern revealed in the innovation management literature - that is, the diffusion results showed the typical s-curves. Further, the model is based on well-established theory, particularly the conceptual framework for innovation diffusion by Rogers (2003) and the BDI architecture by Bratman (1987). Then, empirical input validation must ensure that input data is accurate and complies with real-world data. In our application case, input data for parameterization is mainly obtained through workshops with corporate experts (for more information, see the online appendix). In contrast, empirical output validation proved to be particularly challenging because our application case deals with an innovation that will supposedly be introduced only into a possible future market. Obviously, there is no empirical data on innovation diffusion that could be compared with simulation results. Therefore, we performed a historical validation in which we used real-world historical data of a product that has been introduced into market. Information regarding the product as well as sales data were obtained from our industry partner. Figure 5 illustrates simulation results (averaged over ten runs in bold and separate runs in light) as well as actual sales data (dashed) for this product in one plot.

It is fair to argue that such an ex-post validation profits from our efforts to calibrate parameters within permissible limits in order to attain such an agreeable level of congruence between simulation results and actual sales. However, this congruence is only feasible if integral market mechanisms can be mapped sufficiently well by the simulation model's substantial functionality. Based on these results, the simulation model could at least be deemed to be "historically validated." 


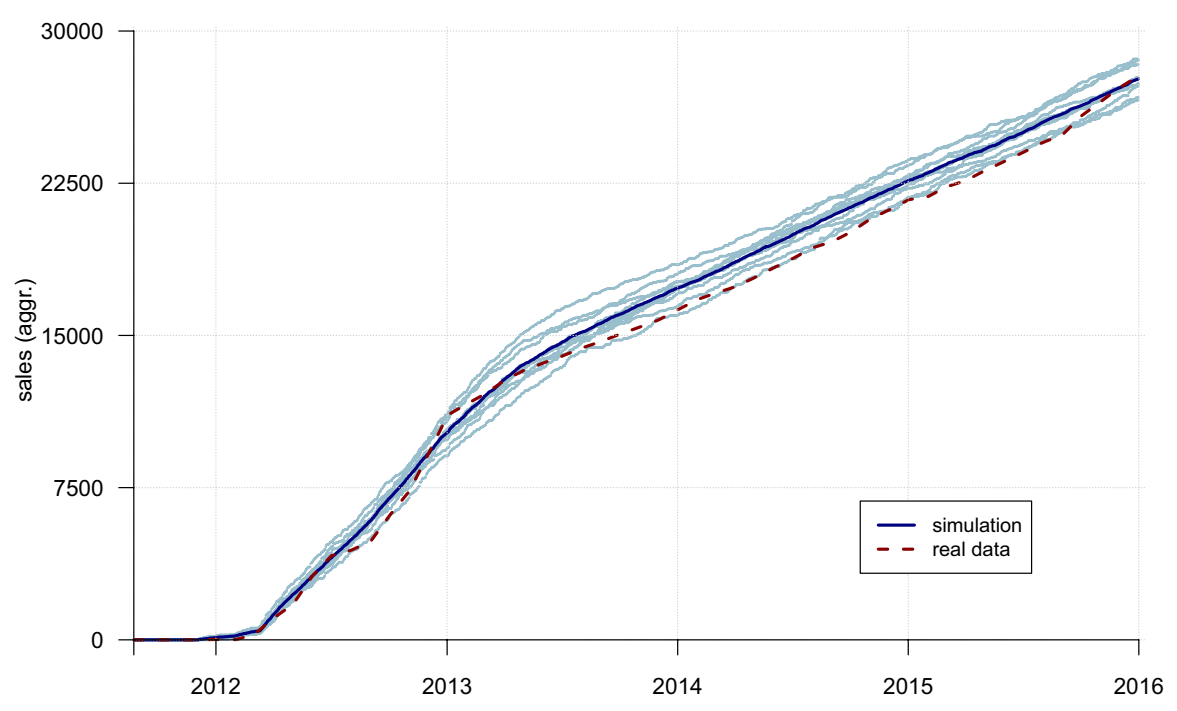

Fig. 5 Historical validation of the market simulation

\subsubsection{Parameterization of consumers}

In our simulation runs, we initialize 8000 consumer agents that represent the population in Germany. Consumer agents are geographically positioned according to household density based on German postal code areas, and the agents are randomly distributed within a $10 \mathrm{~km}$ radius around the geographical center of their respective postal code area. Thus, household density is used as a proxy for population distribution. We consider the resulting inaccuracies as acceptable for the purpose of this application because the geographical distribution is only used for generating the social network but not for determining whether or not consumers have access to a store (given that in our application case, this access is always granted through the online channel).

The parameterization of individual consumer agents certainly poses a challenge. Necessary information regarding consumer preferences can be gathered through a conjoint analysis (for examples, see Garcia and Jager 2011; Klein et al. 2020; Stummer et al. 2015; Zhang et al. 2011) or through representative consumers (so-called "personas") for each group of consumers with similar characteristics and usage behavior (Cooper 1999). In the first case, depending on the number of participants in the empirical study, each agent might be assigned the characteristics of a particular participant from the conjoint study. Alternatively, several agents are based on the characteristics of such a participant and their parameters vary slightly. In the latter case (i.e., when resorting to personas), each agent is assigned to a persona, with the assignment probability corresponding to the proportion of the represented persona in the market. The agent is then parameterized with slight variations of the persona 
so that all agents based on a particular persona have similar but not identical parameters. In our sample application, we followed the personas approach.

The parameterization of attitudes and behaviors of the (consumer) agentsincluding their utility functions for product attributes-is based on data provided by the company, mostly from the marketing department. Procedurally, we conducted workshops with company experts, during which we manually parameterized five representative consumer agents, one from each of five distinct groups of consumers (personas). Note that the corporate experts have a clear perception of the behavior of the personas and provided us with information regarding the size of the respective market segments. Then, the scenarios were accounted for by adapting parameterization for each of the representative agents for each of the four scenarios (i.e., we ended up with $5 \cdot 4=20$ representative agents). For example, the part-worth utility values in the utility functions for smartness functionality and smart-grid capability were directly taken from the description of personas in today's market in Scenario 3, whereas the value of these bending points are increased by $33 \%$ in Scenario 4, in which consumers are expected to highly welcome smart products and services (see Table 1). Consequently, a product's higher level of smartness or connectivity to the smart grid creates higher utility values for a consumer agent in Scenario 4 as compared to the utility values for the same agent in Scenario 3. In the less favorable Scenarios 1 and 2, there is a decrease in the respective values for the bending points in the utility functions. Finally, the parameter values for each individual consumer agent used in the simulation runs are based on the parameterization of the respective representative agent in the particular market segment (persona) and scenario, but are slightly varied, thereby providing us with consumer agents that conform with their respective persona but still are individualized. In all scenarios, we assume that initial awareness for the smart products under investigation is created through marketing campaigns as part of the product launch making some consumer agents aware of the new product and its novel attributes.

For constructing the social network, we use a scale-free network (Barabási and Albert 1999) and extend it with a geographical component (as suggested by Latané et al. 1995) following prior work by Stummer et al. (2015). Network parameters are set to $\alpha=-2$ (geodesic parameter), $\beta=2$, and $n^{\text {edges }}=3$ (clustering parameters) to create a realistic social network with several "hubs". These hubs represent consumer agents with a particularly large number of connections in the social network (Goldenberg et al. 2009), and thus a wider range in spreading information and knowledge (Kratzer and Lettl 2011).

The communication behavior of the consumer agents within their social network was modeled in a straightforward manner based on individual time intervals

Table 1 Consumer agent's parameterization of utility functions in each scenario

\begin{tabular}{lllll}
\hline & Scenario 1 $(\%)$ & Scenario 2 $(\%)$ & Scenario 3 $(\%)$ & Scenario 4 (\%) \\
\hline Smartness & -66 & -33 & \pm 0 & +33 \\
Smart grid & -66 & -33 & \pm 0 & +33 \\
\hline
\end{tabular}


drawn from a triangular distribution. The mode of this triangular distribution depends on the agent's affiliation to a consumer group (persona): for example, agents belonging to persona \#1 are assigned a mode value of 30 days, and the lower and upper limits for the triangular distribution are set to $\pm 25 \%$ - that is, to 22.5 and 37.5 days, respectively. Consumer agents learn about a product through first-hand experience approximately 30 days after purchasing the product; this time interval is drawn from a continuous uniform distribution (25-35 days). Each information is weighted individually depending on how much the consumer agent trusts the information source; first-hand experience has the highest credibility $\left(w_{i}^{\text {fhx }}=1.00\right)$, followed by word-of-mouth communication $\left(w_{i, j}^{\text {wom }}=0.75\right)$, while marketing is deemed to be the least trustworthy information source $\left(w_{i}^{\text {marketing }}=0.50\right)$.

In our sample application, we only considered consumer agents and did not account for competitors (i.e., other producers) and intermediaries. This design decision was due to the excellent market position of the company we worked together: this company is dominant in its particular market segment and has established a considerable distribution network with flagship stores in major cities as well as numerous retailers. Thus, intermediaries-from this company's viewpoint—do not play a relevant role.

\subsubsection{Parameterization of products}

In our market model, products are characterized by four attributes: price, quality, smartness functionality, and smart-grid capability. We are aware that in doing so, several factors - such as, service necessity and availability, or basic functionalityare subsumed by quality and smartness, which is in line with Gigerenzer (2007), who suggests that most decisions are ultimately based on only a few (aggregated) aspects. While the quality level attributed to premium products obviously is higher than the quality level attributed to standard products, there is no difference between the regular and the smart version of a premium product in this respect. Also, the price of a premium product is higher than for a standard product; the price of the smart-premium product is even higher (parameters used for our simulation runs are provided in the online appendix). With respect to smartness of products, we merely distinguish between high smartness, low smartness, and no smartness, the latter occurring only for traditional products from the former product generation. Products with low smartness can be controlled via an app, whereas products with a high level of smartness have additional sensors, actuators, and more means to show (some) autonomy, adaptability, reactivity, multi-functionality, human-like interaction, or ability to cooperate with other appliances in the smart home. Smart-grid capability enables a product to have real-time access to the electricity tariff and let it adapt its operations accordingly.

Purchases only take place when the current product breaks down (i.e., each consumer agent at each point in time possesses exactly one exemplar of the household appliance under investigation in our application case, and they do not consider replacing it before necessary; this assumption very well represents real consumer behavior 
in this particular market). Therefore, we draw from a triangular distribution to account for the lifetime of each product and initiate new purchase transactions when a product reaches the end of its lifetime. The products' lifetime was considerably reduced in our illustrative sample application in order to speed up the diffusion process.

\subsection{Investigated strategy alternatives}

The company sought insight with respect to whether the products from the new product generation must be equipped with smart-grid capabilities and with respect to the necessary level of smartness. These are strategic decisions because developing corresponding products requires a longer planning horizon-that is, in our case, approximately five years from the go-decision until availability of the new generation of products for market introduction. While the smart-grid capability is a binary product attribute (i.e., it is either available or it is not available), the level of smartness can be considered a continuum. For the sake of simplicity, we just distinguish between low smartness and high smartness. If needed, a finer grading of level of smartness and, thus, more strategy alternatives, is possible. As the company experts stated that a high smartness functionality must always go along with smart-grid capability, a few strategy alternatives are excluded. The remaining nine strategies are listed in Table 2.

\subsection{Computational results}

The simulation covered five years, that is, the simulation horizon was set to $5+5=10$ years from the current date. For each combination of a strategy alternative and a scenario, 100 runs with different seeds were performed; the runtime for each set of runs is approximately one hour on a standard notebook. Mean values with respect to the development of market shares for each strategy alternative in each scenario are graphically depicted in Table 3 . Table 4 provides the corresponding numerical values for the market shares of the two novel smart products

Table 2 Strategy alternatives

\begin{tabular}{llllll}
\hline \multirow{2}{*}{$\begin{array}{l}\text { Strategy } \\
\text { alternative }\end{array}$} & \multicolumn{2}{l}{ Smart-standard } & & \multicolumn{2}{l}{ Smart-premium } \\
& Smart grid & Smartness & & Smart grid & Smartness \\
\hline A & Yes & High & & Yes & High \\
B & Yes & Low & & Yes & High \\
C & Yes & High & & Yes & Low \\
D & Yes & Low & & Yes & Low \\
E & No & Low & & Yes & High \\
F & No & Low & & Yes & Low \\
G & Yes & High & & No & Low \\
H & Yes & Low & & No & Low \\
I & No & Low & No & Low \\
\hline
\end{tabular}


Table 3 Market shares for strategy alternatives in the four scenarios

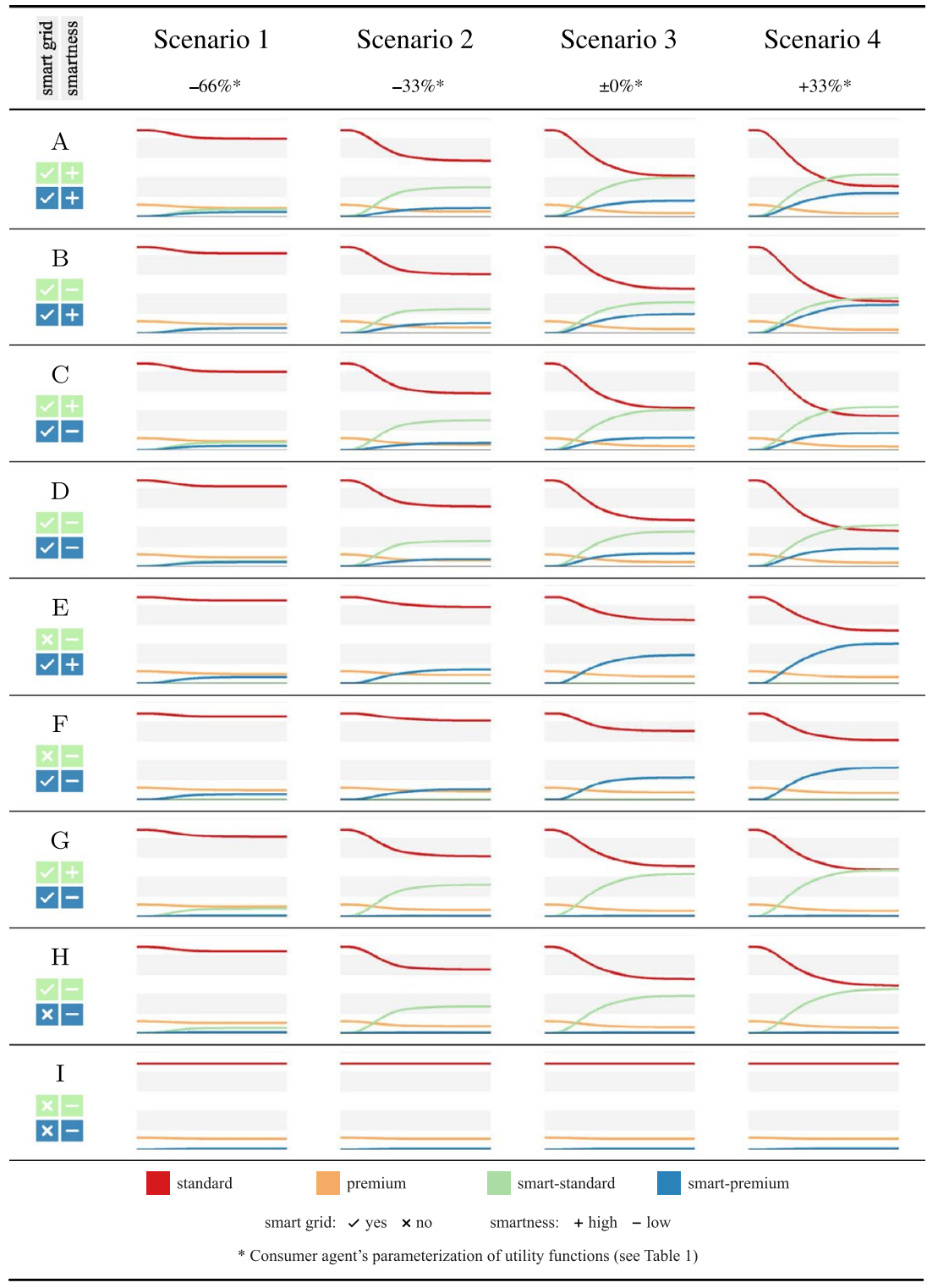

at the end of the simulated period and Table 5 lists the respective variances of these market shares. It must be noted that the variances are rather small.

We also compared the results from our agent-based market simulation with results from an analytical approach in which the same (average) utility function for representative personas are used, and we found that employing the simulation approach indeed makes a difference. The reason for this is the effects of word 
Table 4 Market shares (in \%) of smart-standard (o) and smartpremium product $(\bullet)$

\begin{tabular}{|c|c|c|c|c|c|c|c|c|}
\hline & \multicolumn{2}{|c|}{ Scenario 1} & \multicolumn{2}{|c|}{ Scenario 2} & \multicolumn{2}{|c|}{ Scenario 3} & \multicolumn{2}{|c|}{ Scenario 4} \\
\hline & $\circ$ & • & $\circ$ & - & $\circ$ & - & $\circ$ & $\bullet$ \\
\hline A & 7.3 & 4.6 & 29.7 & 8.5 & 39.5 & 15.9 & 42.5 & 23.7 \\
\hline B & 4.7 & 4.8 & 24.3 & 9.9 & 31.4 & 19.4 & 35.8 & 28.8 \\
\hline $\mathrm{C}$ & 7.5 & 4.0 & 30.3 & 6.7 & 40.8 & 12.4 & 44.0 & 17.0 \\
\hline D & 5.0 & 4.1 & 25.8 & 7.1 & 35.6 & 13.0 & 42.1 & 18.2 \\
\hline $\mathrm{E}$ & 0.0 & 6.0 & 0.0 & 13.8 & $<0.1$ & 28.8 & $<0.1$ & 40.2 \\
\hline $\mathrm{F}$ & 0.0 & 5.2 & 0.0 & 10.5 & $<0.1$ & 22.4 & $<0.1$ & 32.6 \\
\hline G & 7.9 & 0.8 & 31.9 & 0.5 & 42.9 & 0.5 & 46.8 & 0.5 \\
\hline $\mathrm{H}$ & 5.3 & 0.8 & 27.4 & 0.5 & 38.1 & 0.5 & 45.3 & 0.5 \\
\hline I & 0.0 & 0.8 & 0.0 & 0.9 & $<0.1$ & 0.9 & 0.1 & 0.9 \\
\hline
\end{tabular}

\begin{tabular}{|c|c|c|c|c|c|c|c|c|}
\hline & \multicolumn{2}{|c|}{ Scenario 1} & \multicolumn{2}{|c|}{ Scenario 2} & \multicolumn{2}{|c|}{ Scenario 3} & \multicolumn{2}{|c|}{ Scenario 4} \\
\hline & $\circ$ & $\bullet$ & ० & $\bullet$ & ० & $\bullet$ & $\circ$ & • \\
\hline A & 0.23 & 0.06 & 0.51 & 0.11 & 0.32 & 0.16 & 0.17 & 0.17 \\
\hline B & 0.07 & 0.08 & 0.37 & 0.17 & 1.76 & 1.02 & 0.61 & 0.41 \\
\hline $\mathrm{C}$ & 0.21 & 0.05 & 0.44 & 0.08 & 0.31 & 0.13 & 2.10 & 0.43 \\
\hline D & 0.11 & 0.06 & 0.27 & 0.08 & 0.67 & 0.12 & 0.14 & 0.13 \\
\hline E & 0.00 & 0.11 & 0.00 & 0.18 & $<0.01$ & 0.90 & $<0.01$ & 0.19 \\
\hline $\mathrm{F}$ & 0.00 & 0.09 & 0.00 & 0.14 & $<0.01$ & 0.50 & $<0.01$ & 0.37 \\
\hline G & 0.20 & 0.01 & 0.48 & 0.01 & 0.32 & 0.01 & 0.14 & 0.01 \\
\hline $\mathrm{H}$ & 0.10 & 0.01 & 0.24 & 0.01 & 0.58 & 0.01 & 0.13 & 0.01 \\
\hline I & 0.00 & 0.01 & 0.00 & 0.01 & $<0.01$ & 0.01 & $<0.01$ & 0.01 \\
\hline
\end{tabular}

Table 5 Variance of market shares of smart-standard (o) and smart-premium product $(\bullet)$

of mouth and normative social influence, both of which cannot be suitably captured through traditional analysis. This finding is consistent with results reported by Rand and Rust (2011), who studied the effect of considering consumer agent interaction in a social network and concluded that allowing such interactions in several cases enables a more accurate prediction of innovation diffusion (tested with real-world data from previous applications of the Bass model).

\subsection{Discussion and managerial insights}

Simulation results are plausible in that market shares of smart products are larger in scenarios in which higher enthusiasm for smart products is assumed than in the less favorable scenarios - that is, for each strategy, the combined market shares of the smart products are larger in Scenarios 3 and 4 than in Scenarios 1 and 2 [see Table 6; note that even for Strategy I the market share is higher in Scenario $3(0.92 \%)$ than in Scenario $2(0.89 \%)$ ]. Furthermore, it is hardly surprising that if products provide higher utility (i.e., they are equipped with a higher level of smartness or with 
Table 6 Combined market shares (in \%) of smart-standard and smart-premium product

\begin{tabular}{lclll}
\hline & Scenario 1 & Scenario 2 & Scenario 3 & Scenario 4 \\
\hline A & 11.9 & 38.2 & 55.4 & 66.2 \\
B & 9.5 & 34.2 & 50.8 & 64.6 \\
C & 11.5 & 37.0 & 53.2 & 61.0 \\
D & 9.1 & 32.9 & 48.6 & 60.3 \\
E & 6.0 & 13.8 & 28.8 & 40.2 \\
F & 5.2 & 10.5 & 22.4 & 32.6 \\
G & 8.7 & 32.4 & 43.4 & 47.3 \\
H & 6.1 & 27.9 & 38.6 & 45.8 \\
I & 0.8 & 0.9 & 0.9 & 1.0 \\
\hline
\end{tabular}

smart-grid capabilities), these products more often than not will gain some market share. However, from a managerial perspective, the more interesting questions are (i) to which extent such product features pay off and whether and, if so, to which extent these pay-offs differ in the futures taken into consideration, (ii) which groups of consumers are responsible for shifts between market shares, and (iii) how market diffusion of the new products develops over time.

When analyzing simulation results for this sample application with respect to the first set of questions, decision-makers can draw two general findings. First, higher levels of smartness indeed pay off in terms of market share, as smart products with a high level of smartness generate a higher market share than smart products with a low level of smartness. However, this outcome is mainly provoked through the assumption of identical prices for the smart products independently from their level of smartness: smart-standard products with a low smartness level (e.g., in Strategy B) have the same price as smart products with a high smartness level (e.g., in Strategy A); this is also true for smart-premium products with low or high levels of smartness, respectively (e.g., in Strategy C vs. Strategy A). This parameterization followed information provided from the company experts who we spoke to; the reasoning is that the company typically sets target prices-in this case, for smartstandard products and for smart-premium products - and does not (primarily) derive these prices from actual costs for research and development. Nevertheless, in several instances, the level of smartness does not cause considerable differences in combined market shares for the two smart products when comparing the corresponding strategy alternatives: for example, the difference in markets shares for smart products between Strategies A and C is only $2.2 \%$ in Scenario 3 and $0.4 \%$ in Scenario 1. However, in other instances, the level of smartness makes a more pronounced difference: for example, it is 5.2\% between the Strategies A and C in Scenario 4; differences are also substantial between Strategies E and F, and between Strategies G and $\mathrm{H}$. In a nutshell, in this particular future market, equipping smart products with a low level of smartness functionality might be sufficient in some instances, but it can backfire in other instances.

Second, simulation results suggest that smart-grid capability also has an impact. In the most extreme instance-that is, in Strategy I in which none of the smart 
products provide smart-grid capability (and also feature only a low level of smartness)_combined market share is just one percent or less. In the adverse Scenarios 1 and 2, opting for a low-smart standard product without smart-grid capability-that is, in Strategies E, F, and I-even result in no market share for this novel product at the end of the simulated period. It is noteworthy that in Strategies E-H, in which only one of the novel products has the smart-grid capability, this particular product gains the lion share of sales. However, higher sales from this product cannot compensate the very low sales of the product without smart-grid capability. For example, Strategies D and F just differ in the smart-grid capability of the smart-standard product; nevertheless, the combined market share is $48.6 \%$ for Strategy D in Scenario 3 and only $22.4 \%$ for Strategy $F$ in the same scenario (this applies analogously for the other scenarios, as well as for a comparison of Strategies D and H). In a nutshell, when developing products with a low smartness level for this future market, equipping them with smart-grid capabilities is a must.

In addition to predicting market shares in future markets, simulation data also hints at which groups of consumers-in this sample application, the personasare responsible for shifts between the market shares of products. Such information might become valuable when (later on) designing short-term marketing campaigns to accompany product introduction. The switching behavior presented in Fig. 6 provides an example for such an analysis that can be performed for both the entire market (demonstrated on the left-hand side of the figure) and for individual groups of consumers (in the middle and on the right-hand side).

From these exemplary analyses, it is evident that in Scenario 4, in which consumers are very open-minded to smart products, employing Strategy A results in approximately two thirds of the former standard product users to purchase one of the two smart products once their existing product requires replacement-more

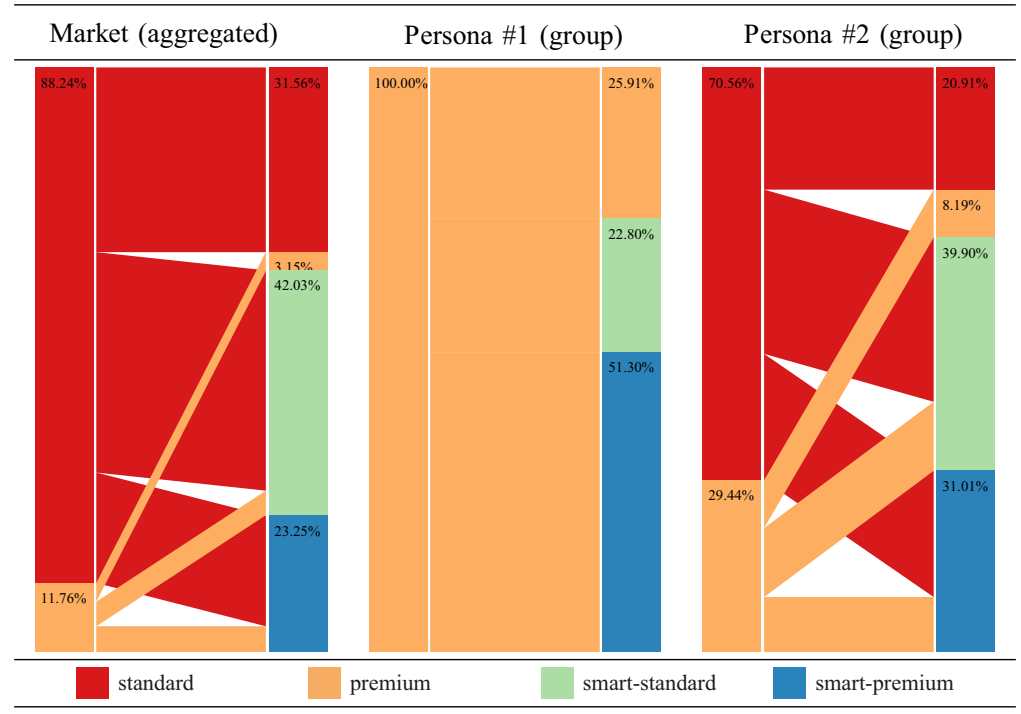

Fig. 6 Switching behavior in Scenario 4 for Strategy A (taken from a single run) 
precisely, $43 \%$ of them opt for the smart-standard product and $21 \%$ for the smartpremium product (the relative shares of switching consumers are not shown in Fig. 6 for the sake of clarity). The reasons for the relatively high share of former standard product users purchasing the smart-premium product might include normative social influence by their peers, receiving particularly favorable information regarding the premium product through word of mouth, or that quality is of high importance for them (indeed, the quality of the smart-standard product slightly decreased in comparison with the non-smart standard product following the suggestion of a company expert who expected a few problems with such a product in its infancy, and it is considerably lower than that for the smart-premium product). Among the former premium buyers, almost one third (27\%) stick to the non-smart (premium) product, because they are not interested in the smartness functionality. The second third of consumers $(36 \%)$ switches to a smart-standard product, which is in the same price range as the former non-smart premium product, because they gain more utility from product smartness than from superior product quality and do not want to pay more than before. The last third of former premium users $(37 \%)$ look for both smartness functionalities and high product quality, and they are comparatively priceinsensitive; therefore, these consumers purchase the smart-premium product.

Analysis of simulation results is also possible at the level of personas, which reveals more differentiated results. For example, persona \#1 in this application case is referred to as the (small) group of high-income consumers who focus on success and perfection. Consequently, all these consumers currently own a premium product, assuming that it best meets their expectations; $26 \%$ of the consumers from this group stick with the non-smart premium product, always buying the same type of product due to lack of interest and no time to deal with the pros and cons of switching to a smart product version. Rather surprisingly, $23 \%$ downgrade to a smartstandard product over time, because the smartness functionality appears to outrank superior quality for consumers from this persona group who are somewhat (in spite of their high income) more price-sensitive. Nevertheless, the largest proportion of consumers from this group (51\%) opt for the smart-premium product in their next purchasing decision (either because they highly value both quality and smartness of the product, or, presumably, for reasons of reputation and because they simply always purchase the most exclusive and expensive type of product).

Consumers from persona \#2, depicted on the right-hand side of Fig. 6, are (late) middle-aged, live in their own suburban house, and have a well-paid job, which provides them with a relatively high standard of living. Approximately $40+31=71 \%$ of these consumers buy a smart product within the simulation horizon. Almost $31 \%$ of the former standard product owners from this persona group switches to a smartpremium product, while $40 \%$ of former users of the premium product then choose the smart-standard version. However, in absolute market shares, the proportion of (non-smart plus smart) premium products increases from $29 \%$ to $8+31=39 \%$. The unexpected switching behavior of certain consumers-for example, from a nonsmart standard product to a smart-premium product — can be further analyzed at the agent level.

An example of the diffusion of the new (smart) products over time (still for Strategy A in Scenario 4) is illustrated in Fig. 7. The reason for the relatively quick 
adoption of the new products can be attributed to the application case in which consumer agents are familiar with this product class. Once they experience a sufficiently high utility value, consumers immediately purchase the smart product without spending considerable effort in further information seeking. For markets with different characteristics, the simulation could be easily adapted to more reluctant consumer behavior. As has already been indicated in Table 5, the variance is apparently small, as indicated by the (100) diffusion curves in light colors; the average overall run is shown as a dark-colored curve.

If decision-makers in our sample application solely strive for large market shares of the novel smart products, they must implement Strategy A, which provides the highest (combined) market shares in all four scenarios. This outcome could have been expected (due to the company's pricing strategy described earlier)—at least, as long as market share remains the only decision criterion. However, if profit comes into play as a decision criterion and, thus, costs for developing the smartness features are taken into account, the picture very well might be different, with other strategies become favorable in the various scenarios. For our sample application, we did not receive sufficient information on costs from the company we cooperated with and, therefore, we have been unable to show results with respect to the profit criterion. Once different strategies are favorable in different futures, decision-makers either can dedicate one scenario as the most likely one and implement the most effective strategy for this particular scenario, they can perform a minimax analysis (Wald 1939) or a minimax-regret analysis (Savage 1951), they can choose some other means from the toolbox of multi-criteria decision analysis for aggregating several performance indicators taken from the market simulation, or they can use a decision support system and graphically represent the objective values of the strategy alternatives (for examples, see Gettinger et al. 2013). The agent-based simulation provides them with all required information. The simulation would even enable the testing of dynamic (price) strategies such as raising or lowering prices with respect to sales for

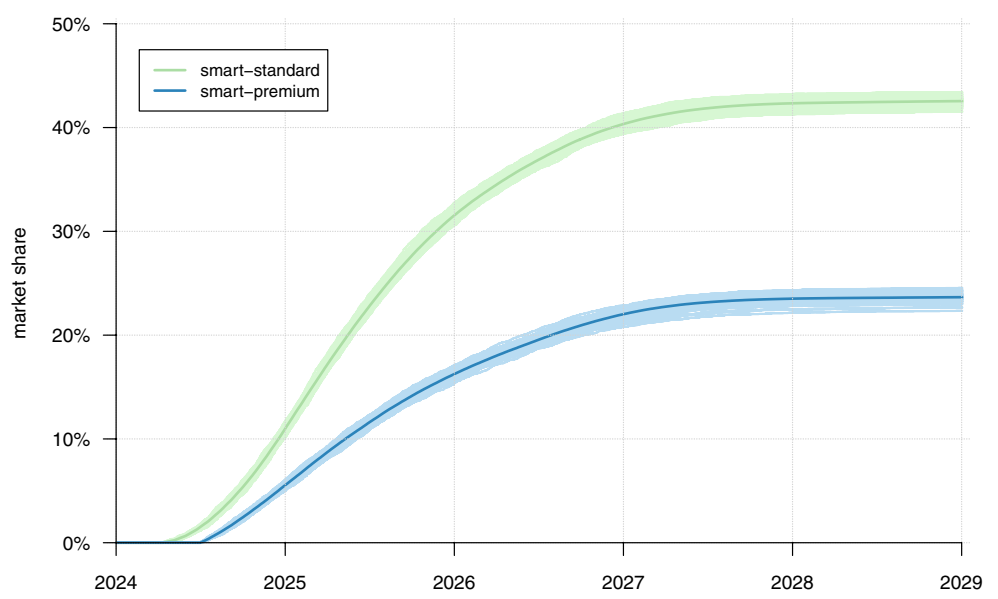

Fig. 7 Diffusion of the new smart products for Strategy A in Scenario 4 
specific products or other indicators. In other words, such a simulation tool provides decision-makers with a virtual sandbox in which all sorts of strategies can be tested.

\section{Conclusions}

The proposed multi-method approach combines an agent-based market simulation with an upstream scenario analysis that translates current market information into a set of parameters to be used for analyzing alternative future markets and different strategy alternatives. This approach not only enables decision-makers to analyze dynamic effects and developments over time (e.g., grow or decline of products' market shares or sales for further financial analysis), but also enables a more in-depth analysis of consumer-switching behavior between products or product categories induced by newly introduced products or features. An exemplary application case based on real-world data illustrates our approach.

On the downside, performing the scenario analysis, collecting data for parameterizing the current market, and deriving appropriate parameter sets for the future market is not trivial but requires expert knowledge and can be costly in terms of monetary resources (e.g., for conducting a conjoint analysis to learn about consumers utility functions) and time (e.g., workshops with practitioners for beaming market information to fit in the pictures of the future). Further, verification and validation of the (agent-based) market model, as with all simulation approaches, is challenging. Finally, before implementing such a powerful approach, it must be critically examined whether the (additional) benefits justify the associated costs.

The agent-based model and its illustrative application case are subject to limitations in two respects. First and foremost, all costs are excluded and the analysis is conducted exclusively on the basis of market shares, as detailed information about fixed costs or marginal returns were kept confidential by the company. Second, pricing parameters set by the company considerably limit the variability of simulation outcome: as price for the smart-standard or smart-premium product version is fixed regardless of whether the new product is equipped with a low level or a high level of smartness functionality or whether or not it provides smart-grid capabilities, it suggests itself that Strategy A in all scenarios turns out to be the most favorable one with respect to market share of smart products (still, the size of the market shares varies, which is of practical relevance). Different strategy recommendations can be expected if prices between the versions of the smart products differ (or if profit is taken into account as an additional objective).

Future research can be pursued in several directions. First, the agent-based simulation could be extended in order to allow for more active behavior of producers, intermediaries, and competitors, each with their own individual (strategic) behavior. Then, more elaborated modeling approaches from prior research on opinion dynamics or social influence processes could be integrated in the agent-based market simulation; promising works that can serve as starting point for further research may originate from-or be inspired by-diverse disciplines such as management science (e.g., Bianchi et al. 2020; Rand and Stummer 2021; 
Sonderegger-Wakolbinger and Stummer 2015), mathematics (e.g., Banisch and Olbrich 2019), philosophy (e.g., Hegselmann and Krause 2002), physics (e.g., Banisch et al. 2010; Castellano et al. 2009; Sobkowicz 2018), political science (e.g., Axelrod 1997), psychology (e.g., Wolf et al. 2015), and sociology (e.g., Friedkin et al. 2009; Keijzer et al. 2020; Mäs and Flache 2013). Next, interventions by the government could be taken into account as well, for example, by lowering product price because of subsidies offered or when expecting the non-continuity of certain competing products due to future regulations (e.g., with respect to obligatory energy-saving guidelines). Further, different scenario techniques may be evaluated for a possibly simpler or more precise beaming of market characteristics and data into the future. Finally, our approach could be applied for additional (diverse) markets with various characteristics.

Supplementary Information The online appendix is available at https://doi.org/10.1007/ s11573-021-01046-9.

Acknowledgements Financial support from the Federal Ministry of Education and Research (BMBF) for the sustainability project "itsowl-VorZug" as part of the BMBF leading-edge cluster "it's OWL" is gratefully acknowledged (Grant no. 02PQ3023). Moreover, we thank our three network partners-Heinz Nixdorf Institute (HNI) at Paderborn University, Scenario Management International AG (ScMI), and UNITY Consulting and Innovation AG-for their cooperation and for sharing their expertise on scenario analysis.

Funding Open Access funding enabled and organized by Projekt DEAL.

Conflict of interest The authors declare that they have no conflict of interest.

Open Access This article is licensed under a Creative Commons Attribution 4.0 International License, which permits use, sharing, adaptation, distribution and reproduction in any medium or format, as long as you give appropriate credit to the original author(s) and the source, provide a link to the Creative Commons licence, and indicate if changes were made. The images or other third party material in this article are included in the article's Creative Commons licence, unless indicated otherwise in a credit line to the material. If material is not included in the article's Creative Commons licence and your intended use is not permitted by statutory regulation or exceeds the permitted use, you will need to obtain permission directly from the copyright holder. To view a copy of this licence, visit http://creativecommons.org/licen ses/by/4.0/.

\section{References}

Amer M, Daim TU, Jetter A (2013) A review of scenario planning. Futures 46:23-40

AnyLogic (2020) Simulation modeling software tools \& solutions for business. https://www.anylogic. com. Accessed 29 Dec 2020

Aral S, Walker D (2014) Tie strength, embeddedness, and social influence: a large-scale networked experiment. Manag Sci 60(6):1352-1370

Axelrod R (1997) The dissemination of culture: a model with local convergence and global polarization. J Conflict Resolut 41(2):203-226

Backs S, Günther M, Stummer C (2019) Stimulating academic patenting in a university ecosystem: an agent-based simulation approach. J Technol Transf 44(2):434-461

Banisch S, Olbrich E (2017) The coconut model with heterogeneous strategies and learning. J Artif Soc S 20(1): 14

Banisch S, Olbrich E (2019) Opinion polarization by learning from social feedback. J Math Sociol 43(2):76-103 
Banisch S, Araújo T, Louçã J (2010) Opinion dynamics and communication networks. Adv Complex Syst 13(1):95-111

Baptista M, Martinho CR, Lima F, Santos PA, Prendinger H (2014) Improving learning in business simulations with an agent-based approach. J Artif Soc Soc Simul 17(3):7

Barabási AL, Albert R (1999) Emergence of scaling in random networks. Science 286(5439):509-512

Bass FM (1969) A new product growth for model consumer durables. Manag Sci 15(5):215-227

Bearden WO, Rose RL (1990) Attention to social comparison information: an individual difference factor affecting consumer conformity. J Con Res 16(4):461-471

Bianchi F, Flache A, Squazzoni F (2020) Solidarity in collaboration networks when everyone competes for the strongest partner: a stochastic actor-based simulation model. J Math Sociol 44(4):249-266

Bishop P, Hines A, Collins T (2007) The current state of scenario development: an overview of techniques. Foresight $9(1): 5-25$

Bradfield R, Wright G, Burt G, Cairns G, van der Heijden K (2005) The origins and evolution of scenario techniques in long range business planning. Futures 37(8):795-812

Bratman M (1987) Intention, plans, and practical reason. Harvard University Press, Cambridge

Butcher K, Sparks B, O'Callaghan F (2002) Effect of social influence on repurchase intentions. J Serv Mark 16(6):503-514

Castellano C, Fortunato S, Loreto V (2009) Statistical physics of social dynamics. Rev Mod Phys 81(2):561-646

Cialdini RB, Goldstein NJ (2004) Social influence: compliance and conformity. Annu Rev Psychol 55:591-621

Cooper A (1999) The inmates are running the asylum: why high-tech products drive us crazy and how to restore the sanity. Sams, Indianapolis

Delre SA, Jager W, Bijmolt TH, Janssen MA (2010) Will it spread or not? The effects of social influences and network topology on innovation diffusion. J Prod Innov Manag 27(2):267-282

Derbyshire J, Wright G (2017) Augmenting the intuitive logics scenario planning method for a more comprehensive analysis of causation. Int J Forecast 33(1):254-266

Deutsch M, Gerard HB (1955) A study of normative and informational social influences upon individual judgment. J Abnor Soc Psych 51(3):629-636

Epstein JM (1999) Agent-based computational models and generative social science. Complexity 4(5):41-60

Fagiolo G, Moneta A, Windrum P (2007) A critical guide to empirical validation of agent-based models in economics: methodologies, procedures, and open problems. Comput Econ 30(3):195-226

Fink A, Schlake O (2000) Scenario management: an approach for strategic foresight. Compet Intell Rev 11(1):37-45

Fink A, Siebe A (2011) Handbuch Zukunftsmanagement: Werkzeuge der strategischen Planung und Früherkennung. Campus Verlag, Frankfurt [in German]

Frank M, Echterhoff B (2018) Die Zukunft der Energietechnik. In: Siebe A (ed) Die Zukunft vorausdenken und gestalten: Intelligente Technische Systeme - Lösungen aus dem Spitzencluster it's OWL. Springer, Berlin, pp 55-64 [in German]

Friedkin NE, Proskurnikow AV, Temp R, Parsegov SE (2009) Network science on belief system dynamics under logic constraints. Science 354(6310):321-326

Garcia R, Jager W (2011) From the special issue editors: agent-based modeling of innovation diffusion. J Prod Innov Manag 28(2):148-151

Gausemeier J, Fink A, Schlake O (1998) Scenario management: an approach to develop future potentials. Technol Forecast Soc Chang 59(2):111-130

Gettinger J, Kiesling E, Stummer C, Vetschera R (2013) A comparison of representations for discrete multicriteria decision problems. Decis Support Syst 54(2):976-985

Gigerenzer G (2007) Gut feelings: the intelligence of the unconscious. Penguin, New York

Godet M (1987) Scenarios and strategic management. Butterworths, London

Goldenberg J, Han S, Lehmann DR, Hong JW (2009) The role of hubs in the adoption process. J Mark 73(2): $1-13$

Golder PN, Tellis GJ (2004) Growing, growing, gone: cascades, diffusion, and turning points in the product life cycle. Market Sci 23(2):207-218

Grimm V, Railsback SF (2005) Individual-based modeling and ecology. Princeton University Press, Princeton

Günther M, Lüpke L, Stummer C (2017) Cross-over between scenario analysis and agent-based market simulation for technology planning. In: Proceedings of the Portland international conference on management of engineering and technology 2017 (PICMET), IEEE, pp 1-9 
Hegselmann R, Krause U (2002) Opinion dynamics and bounded confidence models, analysis, and simulation. J Artif Soc 5(3):2

Huss WR, Honton E (1987) Alternative methods for developing business scenarios. Technol Forecast Soc Change 31(3):219-238

it's OWL (2020) The technology network: intelligent technical systems OstWestfalenLippe. https://www.itsowl.com/. Accessed 29 Dec 2020

Kahn H, Wiener AJ (1967) The year 2000: a framework for speculation on the next thirty-three years. Macmillan, New York

Keijzer MA, Mäs M, Flache A (2020) Communication in online social networks fosters cultural isolation. Complexity Article ID 9502872

Kiesling E, Günther M, Stummer C, Wakolbinger LM (2012) Agent-based simulation of innovation diffusion: a review. Cen Euro J Oper Res 20(2):183-230

Klein D, Marx J, Fischbach K (2018) Agent-based modeling in social science, history, and philosophy: an introduction. Hist Soc Res 43(1):7-27

Klein M, Lüpke L, Günther M (2020) Home charging and electric vehicle diffusion: agent-based simulation using choice-based conjoint data. Transp Res D Transp Environ 88:102475

Knepell P, Arangno D (1992) Simulation validation: a confidence assessment methodology. IEEE Computer Society Press, Los Alamitos

Kratzer J, Lettl C (2011) Die Identifizierung von Lead Usern über soziale Netzwerke: Eine empirische Untersuchung unter jungen Konsumenten. Z Betriebswirtsch 81(5):83-109 [in German]

Latané B (1981) The psychology of social impact. Am Psycho 36(4):343-356

Latané B, Liu JH, Nowak A, Bonevento M, Zheng L (1995) Distance matters: physical space and social impact. Pers Soc Psycho Bull 21(8):795-805

Macal CM (2016) Everything you need to know about agent-based modelling and simulation. J Sim $10(2): 144-156$

Mäs M, Flache A (2013) Differentiation without distancing: explaining bi-polarization of opinions without negative influence. PLoS One 8(11):e74516

Millett SM (2003) The future of scenarios: challenges and opportunities. Strat Leadersh 31(2):16-24

Negahban A, Yilmaz L (2014) Agent-based simulation applications in marketing research: an integrated review. J Sim 8(2):129-142

North MJ, Macal CM (2007) Managing business complexity: discovering strategic solutions with agentbased modeling and simulation. Oxford University Press, New York

OECD (2021) Main science and technology indicators 2020/2. OECD Publishing, Paris

Ormerod P, Rosewell B (2006) Validation and verification of agent-based models in the social sciences. International workshop on epistemological aspects of computer simulation in the social sciences. Springer, Berlin, pp 130-140

Raff S, Wentzel D, Obwegeser N (2020) Smart products: conceptual review, synthesis, and research directions. J Prod Innov Manag 37(5):379-404

Rahmandad H, Sterman J (2008) Heterogeneity and network structure in the dynamics of diffusion: comparing agent-based and differential equation models. Manag Sci 54(5):998-1014

Rand W, Rust RT (2011) Agent-based modeling in marketing: guidelines for rigor. Int J Res Mark 28(3):181-193

Rand W, Rust RT, Kim M (2018) Complex systems: marketing's new frontier. AMS Rev 8(3-4):111-127

Rand W, Stummer C (2021) Agent-based modeling of new product market diffusion: an overview of strengths and criticisms. Ann Oper Res (forthcoming)

Rigby D, Bilodeau B (2007) Selecting management tools wisely. Harv Bus Rev 85(12):20-22

Rijsdijk SA, Hultink EJ (2009) How today's consumers perceive tomorrow's smart products. J Prod Innov Manag 26(1):24-42

Risselada H, Verhoef PC, Bijmolt TH (2014) Dynamic effects of social influence and direct marketing on the adoption of high-technology products. J Mark 78(2):52-68

Rogers EM (2003) Diffusion of innovations, vol 5. Free Press, New York

Roper A, Cunningham S, Porter A, Mason T, Rossini F, Banks J (2011) Forecasting and management of technology, vol 2. Wiley, New York

Savage LJ (1951) The theory of statistical decision. J Am Stat Assoc 46(253):55-67

Scheller F, Johanning S, Bruckner T (2019) A review of designing empirically grounded agent-based models of innovation diffusion: development process, conceptual foundation and research agenda. Institute for Infrastructure and Resources Management (IIRM), University Leipzig 
Schlange LE (1995) Linking futures research methodologies: an application of systems thinking and metagame analysis to nuclear energy policy issues. Futures $27(8): 823-838$

Schwering A (2017) The influence of peer honesty and anonymity on managerial reporting. J Bus Econ 87(9):1151-1172

Sobkowicz P (2018) Opinion dynamics model based on cognitive biases of complex agents. J Artif Soc 21(4):8

Sonderegger-Wakolbinger L, Stummer C (2015) An agent-based simulation of customer multi-channel choice behavior. Cen Euro J Oper Res 23(2):459-477

Stummer C, Kiesling E, Günther M, Vetschera R (2015) Innovation diffusion of repeat purchase products in a competitive market: an agent-based simulation approach. Eur J Oper Res 245(1):157-167

Stummer C, Lüpke L, Backs S, Günther M (2018) Agentenbasierte Simulation: Ein Spezialwerkzeug. In: Siebe A (ed) Die Zukunft vorausdenken und gestalten: Intelligente Technische Systeme - Lösungen aus dem Spitzencluster it's OWL. Springer, Berlin, pp 125-142 [in German]

Teschner F, Weinhardt C (2015) A macroeconomic forecasting market. J Bus Econ 85(3):293-317

van Eck PS, Jager W, Leeflang PSH (2011) Opinion leaders' role in innovation diffusion: a simulation study. J Prod Innov Manag 28(2): 187-203

Wack P (1985) Scenarios: uncharted waters ahead. Harv Bus Rev 63(5):73-89

Wakolbinger LM, Stummer C, Günther M (2013) Market introduction and diffusion of new products: recent developments in agent-based modeling. Int J Innov Technol Manag 10(5):1-19

Wald A (1939) Contributions to the theory of statistical estimation and testing hypotheses. Ann Math Stat 10(4):299-326

Watts DJ, Strogatz SH (1998) Collective dynamics of 'small-world' networks. Nature 393(6684):440-442

Wolf I, Schröder T, Neumann J, de Haan G (2015) Changing minds about electric cars: an empirically grounded agent-based modeling approach. Technol Forecast Soc Chang 94:269-285

Zhang T, Gensler S, Garcia R (2011) A study of the diffusion of alternative fuel vehicles: an agent-based modeling approach. J Prod Innov Manag 28(2):152-168

Publisher's Note Springer Nature remains neutral with regard to jurisdictional claims in published maps and institutional affiliations. 